\section{Global Journal of Business, Economics and Management}

www.wjbem.eu

\title{
Multi-objective green supply chain network optimization
}

Seval Ene*, Industrial Engineering Department, Faculty of Engineering, Uludag University, Bursa 16059, Turkey. Nursel Ozturk, Industrial Engineering Department, Faculty of Engineering, Uludag University, Bursa 16059, Turkey.

\section{Suggested Citation:}

Ene, S. \& Ozturk, N. (2017). Multi-objective green supply chain network optimization. Global Journal of Business, Economics and Management: Current Issues. 7(1), 15-24.

Received November 13, 2016; revised January 30, 2017; accepted March 8, 2017;

Selection and peer review under responsibility of Prof. Dr. Andreea Iluzia IACOB, Bucharest Academy of Economic Studies, Romania.

${ }^{\circledR}$ 2017SciencePark Research, Organization \& Counseling. All rights reserved.

\begin{abstract}
In supply chain management, economical objectives have traditionally guided decisions of the supply chains. However, with increased global environmental and social concerns, in recent years, green aspects have been incorporated in supply chain decisions. These expansions lead to new research areas about green or sustainable supply chain management that includes applying various green practices in order to reduce negative impact on the environment or providing sustainable development. The purpose of this study is to develop a multi-objective optimization model for determining network design of the green supply chains. In multi-objective frame of the proposed model, total profit maximization and environmental impact minimization objectives are considered in order to obtain best network configuration for economic and environmental performance of the green chain. The proposed model is validated with numerical experiments. Obtained results showed that the model can be used as a strategic decision tool in problems with multi and conflicting objectives.
\end{abstract}

Keywords: green supply chain management, multi-objective modelling, network optimization.

*ADDRESS FOR CORRESPONDENCE: Ilker Kucukoglu, Industrial Engineering Department, Faculty of Engineering, Uludag University, Bursa 16059, Turkey. E-mail address: ikucukoglu@uludag.edu.tr/Tel.: +90-224-294-2078 
Ene, S. \& Ozturk, N. (2017). Multi-objective green supply chain network optimization. Global Journal of Business, Economics and Management: Current Issues. 7(1), 15-24.

\section{Introduction}

In last decades, with increased global environmental and social concerns, environmental performance of a supply chain has a strategic importance as well as economic performance of a supply chain. As a result of globalization of supply chains, long distances in distribution networks result in increasing amount of $\mathrm{CO}_{2}$ emissions (Elhedhli \& Merrick, 2012). Additionally, scarcity in natural resources and growing environmental problems reveal the significance of considering environmental issues and applying green practices in supply chains. Srivastava (2007) defined green supply chain management as "integrating environmental thinking into supply chain management, including product design, material sourcing and selection, manufacturing processes, delivery of the final products to the consumers and end-of-life management of used products". Different terms that adopt similar principles with green supply chain concept are also observed in literature, such as sustainable supply chain, environmental supply chain etc. (Govindan, Khodaverdi \& Vafadarnikjoo, 2015). In green, environmental or sustainable supply chain management, incorporating economic, environmental and social performance measures in supply chains provides development in sustainability of supply chains (Varsei, Soosay, Fahimnia \& Sarkis, 2014).

This paper addresses the problem of network design for green supply chains. Network design is the problem of defining the configuration parameters, such as the number, location, capacities, or types of facilities in the network and allocation amounts between network stages (Tognetti, Grosse-Ruyken \& Wagner 2015). Network design problem has a significant impact on the environmental and economic performance of a supply chain (Pishvaee \& Razmi, 2012). Several researchers studied green supply chain network design problem with varied solution approaches. Some of these studies are summarized as follows. Pishvae and Razmi (2012) developed a multi-objective fuzzy mathematical programming model for the design of environmental supply chain considering cost and environmental impact minimization. Life cycle analysis is used for assessing environmental impacts of different supply chain network structure options. Fahimnia, Sarkis and Eshragh (2015) developed a multi-objective mixed integer non-linear mathematical programming model for the green supply chain planning taking into account carbon emissions, energy consumption and the amount of waste produced. To solve the proposed model nested integrated cross-entropy method is employed. Tognetti et al. (2015) studied the green supply chain network design problem by firstly, applying linear economic and environmental optimization models individually and then applying multi-objective optimization model to understand trade-offs between environmental and economic objectives. Marti, Tancrez and Seifert (2015) proposed a mathematical model for supply chain network design considering trade-off between carbon footprint and responsiveness in supply chains. They analyzed the effects of different carbon policies. Chibeles-Martins, Pinto-Varela, Barbosa-Povoa and Novais (2016) developed a bi-objective meta-heuristic approach based on simulated annealing algorithm for the design and planning of the green supply chains. Coskun, Ozgur, Polat and Gungor (2016) suggested a goal programming model for the solution of green supply chain network design problem on the basis of environmental expectations of the customers.

In the scope of this paper, a multi-objective mathematical model is developed to obtain network structure for green supply chains considering environmental and economic objectives. In multiobjective frame of the proposed model, total profit maximization and environmental impact minimization objectives are considered in order to obtain best network configuration for economic and environmental performance of the green chain. Within the context of environmental impact minimization; $\mathrm{CO}_{2}$ emissions caused from transportation, environmental impact caused from opening new plants or distribution centers/warehouses and environmental impact of manufacturing and handling processes based on used clean technology, recyclable materials, renewable energy etc. are considered.

The remainder of this paper provides problem statement in Section 2, proposed multi-objective network design model and adopted multi-objective model solution approaches in Section 3, experimental results in Section 4 and finally conclusions in Section 5. 


\section{Problem statement}

In this paper, multi-stage, multi-product, multi-component and multi-period green supply chain network design problem is studied. Within the scope of the problem, a generic green supply chain network configuration is considered. The network consists of supplier, manufacturing plant, distribution center/warehouse and customer network stages as presented in Figure 1. The network starts with supplying different product components of product types from suppliers. At manufacturing plant, after manufacturing operations, products are transported to customers via distribution centers/warehouses. In the green supply chain network optimization problem; opening decisions will be given for manufacturing plants and distribution centers/warehouses and material allocation decisions will be given between network stages. All customer demands must be satisfied. All customer locations, potential locations of manufacturing plants, distribution centers/warehouses are known. It is assumed that manufacturing plants and distribution centers/warehouses have capacity limitations and capacities of suppliers can satisfy demands of manufacturing plants. Product flow between the facilities of the same stage is not permitted.

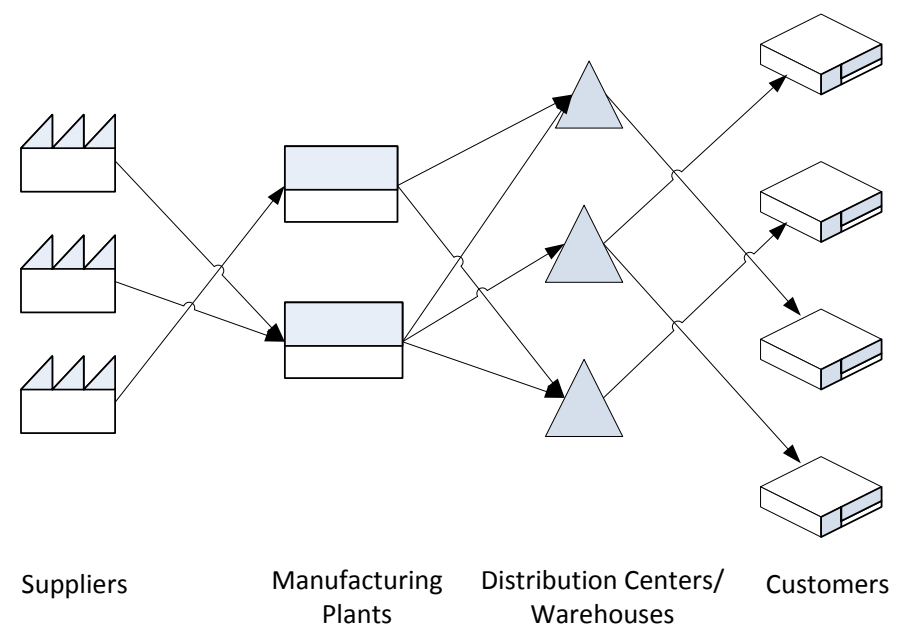

Figure 1. Considered network structure

\section{Model formulation}

Studied green supply chain network design problem is formulated as multi-objective optimization model and to solve the proposed model, weighted sums method and $\varepsilon$-constraint method is used.

\subsection{Multi-objective optimization model}

Sets, decision variables and parameters used in the model, objective functions and constraints are defined as follows:

Sets:

$S \quad$ Set of suppliers $\forall s \in S$

$M \quad$ Set of manufacturing plants $\forall m \in M$

$D \quad$ Set of distribution centers/warehouses $\forall d \in D$

I Set of customers $\forall i \in I$

$P \quad$ Set of products $\forall p \in P$ 
Q Set of components $\forall q \in Q$

$T \quad$ Set of planning periods $\forall t \in T$

Decision Variables:

$a_{m}=\left\{\begin{array}{l}1 \text { if a manufacturing plant opens at location } m \\ 0 \text { otherwise }\end{array}\right.$

$b_{d}=\left\{\begin{array}{l}1 \text { if a distribution center/warehouse opens at location } d \\ 0 \text { otherwise }\end{array}\right.$

$\lambda_{\text {dit }}=\left\{\begin{array}{l}1 \text { if alink created between customer } i \text { and distribution center/warehouse } d \text { during period } t \\ 0 \text { otherwise }\end{array}\right.$

$x_{q s m t}$ Amount of component $q$ transported from supplier $s$ to manufacturing plant $m$ at period $t$

$y_{p m d t}$ Amount of product $p$ transported from manufacturing plant $m$ to distribution center/warehouse $d$ at period $t$

$Z$ pdit Amount of product $p$ transported from distribution center/warehouse $d$ to customer $i$ at period $t$

Parameters:

$c_{m} \quad$ Fixed cost of opening manufacturing plant $m$

$c_{d} \quad$ Fixed cost of opening distribution center/warehouse $d$

$o c_{m} \quad$ Unit operating cost at manufacturing plant $m$

oc $d \quad$ Unit handling cost at distribution center/warehouse $d$

$s c_{q s} \quad$ Unit purchasing cost of component $q$ from supplier $s$

$\mathrm{cap}_{m} \quad$ Capacity of manufacturing plant $m$

$\operatorname{cap}_{d} \quad$ Capacity of distribution center/warehouse $d$

$c t_{s m} \quad$ Transportation distance from supplier $s$ to manufacturing plant $m$

$c t_{m d}$ Transportation distance from manufacturing plant $m$ to distribution center/warehouse $d$

$c t_{d i} \quad$ Transportation distance from distribution center/warehouse $d$ to customer $i$

$u c_{p} \quad$ Unit transportation cost for product $p$

$u c_{q} \quad$ Unit transportation cost for component $q$

bom $_{q p} \quad$ Quantity of component $q$ used in product $p$

$r_{p} \quad$ Unit revenue gained in sold product $p$

dem $_{\text {pit }}$ Demand of customer $i$ to product $p$ over period $t$

A Upper bound for opened manufacturing plants

B Upper bound for opened distribution centers/warehouses

$\alpha \quad$ Emission factor for transportation per unit of weight of products or components and per unit of distance between network stages

$\omega_{p} \quad$ Weight of product $p$

$\omega_{q} \quad$ Weight of component $q$

$\beta_{m} \quad$ Environmental impact level for opening manufacturing plant $m$ 
$\beta_{d} \quad$ Environmental impact level for opening distribution center/warehouse $d$

$\delta_{m} \quad$ Environmental impact level for processes of manufacturing plant $m$

$\delta_{d} \quad$ Environmental impact level for processes of distribution center/warehouse $d$

$N \quad$ Big number

MAPMinimum amount of products that can be sent to the opened distribution centers/warehouses

Objective functions:

$$
\begin{aligned}
\max z_{1} & =\sum_{p \in P} \sum_{d \in D} \sum_{i \in l} \sum_{t \in T} z_{p d i t} r_{p}-\sum_{m \in M} a_{m} c_{m}-\sum_{d \in D} b_{d} c_{d}-\sum_{p \in P} \sum_{m \in M} \sum_{d \in D} \sum_{t \in T} y_{p m d t} o c_{m} \\
& -\sum_{p \in P} \sum_{d \in D} \sum_{i \in l} \sum_{t \in T} z_{p d i t} o c_{d}-\sum_{q \in Q} \sum_{s \in S} \sum_{m \in M} \sum_{t \in T} x_{q s m t} s c_{q s}-\sum_{q \in Q} \sum_{s \in S} \sum_{m \in M} \sum_{t \in T} x_{q s m t} c t_{s m} u c_{q} \\
& -\sum_{p \in P} \sum_{m \in M} \sum_{d \in D t \in T} \sum_{t \in T} y_{p m d t} c t_{m d} u c_{p}-\sum_{p \in P} \sum_{d \in D} \sum_{i \in l} \sum_{t \in T} z_{p d i t} c t_{d i} u c_{p}
\end{aligned}
$$

$\min z_{2}=\sum_{q \in Q} \sum_{s \in S} \sum_{m \in M} \sum_{t \in T} x_{q s m t} \omega_{q} \alpha c t_{s m}+\sum_{p \in P} \sum_{m \in M} \sum_{d \in D} \sum_{t \in T} y_{p m d t} \omega_{p} \alpha c t_{m d}$

$$
\begin{aligned}
& +\sum_{p \in P} \sum_{d \in D} \sum_{i \in l} \sum_{t \in T} z_{p d i t} \omega_{p} \alpha c t_{d i} \\
& \min z_{3}=\sum_{m \in M} a_{m} \beta_{m}+\sum_{d \in D} b_{d} \beta_{d}+\sum_{p \in P} \sum_{m \in M} \sum_{d \in D} \sum_{t \in T} y_{p m d t} \delta_{m}+\sum_{p \in P} \sum_{d \in D} \sum_{i \in l} \sum_{t \in T} z_{p d i t} \delta_{d}
\end{aligned}
$$

Constraints:

$$
\begin{array}{ll}
z_{p d i t}=\text { dem }_{\text {pit }} \lambda_{\text {dit }} & p \in P, d \in D, i \in I, t \in T \\
\sum_{d \in D} \lambda_{\text {dit }}=1 & i \in I, t \in T \\
\sum_{q \in Q s \in S} \sum_{q s m t} x_{q u p_{m}} a_{m} & m \in M, t \in T \\
\sum_{p \in P} \sum_{m \in M} y_{p m d t} \leq \operatorname{cap}_{d} b_{d} & d \in D, t \in T \\
\sum_{s \in S} x_{q s m t}=\sum_{d \in D} \sum_{p \in P} y_{p m d t} b o m_{q p} & q \in Q, m \in M, t \in T \\
\sum_{m \in M} y_{p m d t}=\sum_{i \in I} z_{p d i t} & p \in P, d \in D, t \in T \\
y_{p m d t} \leq N\left(1-\gamma_{p m d t}\right) & p \in P, m \in M, d \in D, t \in T \\
\left(M A P-y_{p m d t} \leq N \gamma_{p m d t}\right. & p \in P, m \in M, d \in D, t \in T \\
\sum_{m \in M} a_{m} \leq \mathrm{A} & \\
\sum_{d \in D} b_{d} \leq \mathrm{B} & \\
x_{q s m t}, y_{p m d t}, z_{p d i t} \geq 0 & p \in P, q \in Q, s \in S, m \in M, d \in D, i \in I, t \in T
\end{array}
$$




$$
a_{m}, b_{d}, \lambda_{d i t}, \gamma_{p m d t} \in\{0,1\} \quad p \in P, m \in M, d \in D, i \in I, t \in T
$$

Objective function (1) maximizes total profit of the network. Objective function (2) minimizes environmental impact caused from transportations between the stages of the network depending on distance and weights of products or components. Objective function (3) minimizes environmental impact arised by opening new plants or centers and environmental impact resulted from processes of manufacturing plants or distribution centers/warehouses. Constraints (4-5) guarantee that all demands of customers must be satisfied in each period for each product type and demands cannot be partitioned. Constraints (6-7) ensure capacity restrictions of manufacturing plants and distribution centers/warehouses in each period. Constraints (8-9) specify flow balance between manufacturing plants and distribution centers/warehouses in each period. Constraints (10-11) ensure minimum allowable product amount level that can be sent to the opened distribution centers/warehouses with a binary variable $\gamma_{p m d t}$. Constraints (12-13) restrict maximum number of manufacturing plants and distribution centers/warehouses that can be opened. Constraint (14) states that decision variables $x, y$ and $z$ must be greater than 0 . Constraint (15) specifies that indicated variables must be 1 or 0 .

\subsection{Solution approaches}

To solve multi-objective problems, weighted sums method or $\varepsilon$-constraint method can be employed. The weighted sums method transforms the problem to a mono-objective optimization problem by combining objective functions with appropriate weights $\left(\psi_{1}, \psi_{2}, \ldots\right)$. The studied problem $\min z=-\psi_{1} z_{1}+\psi_{2} z_{2}+\psi_{3} z_{3} \quad$ can be transformed to the form presented in Equation (16):

s.t. Equations (4 - 15)

$\sum_{i=1}^{3} \psi_{i}=1$

$\psi_{i}>0 \quad i=1,2,3$

In $\varepsilon$-constraint method, the multi-objective optimization problem is transformed to a monoobjective optimization problem with additional constraints. One of the objective functions is considered as objective function and other objectives are written as constraints by using a constraintvectore (Amin\& Zhang, 2013). The studied problem is transformed to the form given in $\max z_{1}$ Equation (17):

s.t. Equations $(4-15)$
$z_{2} \leq \varepsilon_{1}$
$z_{3} \leq \varepsilon_{2}$

\section{Experimental results}

The proposed multi-objective optimization model is validated with an illustrative example. The example includes three product types and six component types. The component requirements for 
each product type are presented in Figure 2. Three suppliers, ten customers, four alternative manufacturing plant locations, six alternative distribution center/warehouse locations and three planning periods are considered in the example. Rest of the parameters of the illustrative example is shown in Table 1. The emission factor value for transportation per unit of weight of products or components and per unit of distance between network stages is utilized from the work of Aksoy, Kucukoglu, Ene and Ozturk (2014). The proposed model is coded in MPL (Mathematical Programming Language) and solved with GUROBI solver.
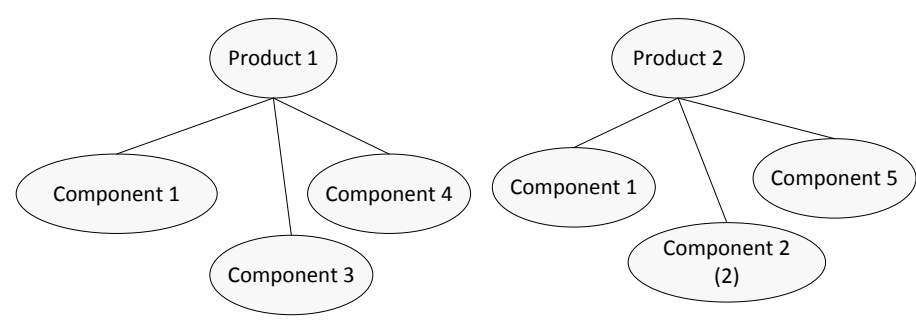

Figure 2. Product types

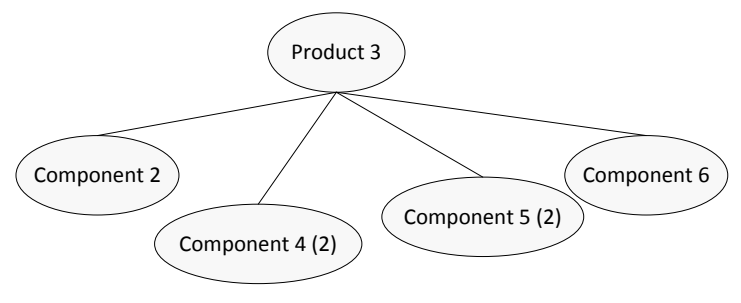

Through the illustrative example, numerous experiments are performed. Firstly, the payoff table is computed as presented in Table 2 . The payoff table showed that $z_{1}$ and $z_{3}$ are contradictory and $z_{1}$ and $z_{2}$ have about a similar trend. Then, pareto optimal solutions are acquired by weighted sums and $\varepsilon$ constraint method.

Table 1. Parameter values of the illustrative example

\begin{tabular}{|c|c|c|c|}
\hline Parameter & Value & Parameter & Value \\
\hline$c_{m}$ & UNIF $(200000,400000)$ & $o c_{m}$ and $o c_{d}$ & 65 and 40 \\
\hline$c_{d}$ & UNIF $(50000,80000)$ & $u c_{p}$ and $u c_{q}$ & 3.5 and 2.5 \\
\hline$c a p_{m}$ & UNIF $(8000,12000)$ & $s c_{q s}$ & UNIF $(20,45)$ \\
\hline$c_{a p}$ & UNIF $(1500,2000)$ & $\alpha$ & 0.427 \\
\hline$c t_{s m}, c t_{m d}$ and $c t_{d i}$ & UNIF $(50,100)$ & $\beta_{m}$ & $(0.7,0.1,0.3,0.9)$ \\
\hline$r_{p}$ & UNIF $(1000,1500)$ & $\beta_{d}$ & $\begin{array}{l}(0.9,0.5,0.3,0.1, \\
0.7,0.8)\end{array}$ \\
\hline dem $_{\text {pit }}$ & UNIF $(150,250)$ & $\delta_{m}$ & $(0.6,0.2,0.3,0.8)$ \\
\hline$\omega_{p}$ & 0.1 & $\delta_{d}$ & $\begin{array}{l}(0.8,0.4,0.2,0.2 \\
0.6,0.9)\end{array}$ \\
\hline$\omega_{q}$ & 0.02 & $\mathrm{~A}$ and $\mathrm{B}$ & 3 and 5 \\
\hline
\end{tabular}

Table 2.Payoff table

\begin{tabular}{lcll}
\hline Objective of the model & Value of $z_{1}$ & Value of $z_{2}$ & Value of $z_{3}$ \\
\hline Max $z_{1}$ & 2491515.50 & 134000.00 & 20862.20 \\
Min $z_{2}$ & 2440076.00 & 133177.99 & 22039.90 \\
Min $z_{3}$ & -4402646.50 & 176608.52 & 10847.30 \\
\hline
\end{tabular}

The pareto optimal solutions are obtained by performing different experiments. The experiments are composed with assigning different weights to the objective functions and with adding different $\varepsilon$ constraints to the model. Some of the efficient solutions obtained from weighted sums and $\varepsilon$ - 
constraint methods are given in Table 3 and Table 4, respectively. Different objective values can be calculated by selecting different $\varepsilon$-constraint levels and weights.

Provided results show that, in weighted sums method, high objective function weight for $z_{1}$ raises profit defined in $z_{1}$, but it brings increased negative impacts on the environment defined in $z_{3}$. As resulted from payoff table, high weight for $z_{1}$ also minimizes $z_{2}$ as $\mathrm{CO}_{2}$ emissions caused from transportations are proportional to the distance and weights of products or components and vice versa for the cases of high weights for $z_{2}$. Nevertheless, high weights for $z_{3}$ result decreased profit values defined in $z_{1}$ and increased $\mathrm{CO}_{2}$ emissions produced from transportation defined in $z_{2}$.

Table 3. Efficient solutions with weighted sums method

\begin{tabular}{lcccccc}
\hline $\begin{array}{l}\text { Number of } \\
\text { Experiment }\end{array}$ & $\psi_{1}$ & $\psi_{2}$ & $\psi_{3}$ & Value of $z_{1}$ & Value of $z_{2}$ & Value of $z_{3}$ \\
\hline 1 & 0.5 & 0.3 & 0.2 & 2473780.50 & 134486.70 & 20165.70 \\
2 & 0.4 & 0.2 & 0.4 & 2395351.00 & 135442.88 & 19339.70 \\
3 & 0.2 & 0.2 & 0.6 & 1233201.00 & 146216.69 & 13435.60 \\
4 & 0.2 & 0.3 & 0.5 & 1664845.00 & 144856.18 & 14808.50 \\
5 & 0.3 & 0.6 & 0.1 & 2488893.50 & 134288.49 & 20516.40 \\
6 & 0.7 & 0.2 & 0.1 & 2489481.50 & 134292.07 & 20535.00 \\
7 & 0.1 & 0.1 & 0.8 & -41685.00 & 154718.17 & 11048.60 \\
8 & 0.3 & 0.4 & 0.3 & 2409067.50 & 135275.54 & 19470.20 \\
\hline
\end{tabular}

Table 4. Efficient solutions with $\varepsilon$ - constraint method

\begin{tabular}{|c|c|c|c|c|c|c|}
\hline $\begin{array}{l}\text { Number of } \\
\text { Experiment }\end{array}$ & $z_{1}$ & $z_{2}$ & $z_{3}$ & Value of $z_{1}$ & Value of $z_{2}$ & $\begin{array}{l}\text { Value of } \\
z_{3}\end{array}$ \\
\hline 1 & $\operatorname{Max} z_{1}$ & $z_{2} \leq 144035.62$ & $z_{3} \leq 16443.60$ & 1956436.50 & 140658.04 & 16443.50 \\
\hline 2 & $\operatorname{Max} z_{1}$ & $z_{2} \leq 165750.89$ & $z_{3} \leq 13645.45$ & 1279234.00 & 145652.45 & 13645.20 \\
\hline 3 & $z_{1} \geq 767975.00$ & $\operatorname{Min} z_{2}$ & $z_{3} \leq 19241.75$ & 2381876.00 & 135601.89 & 19241.70 \\
\hline 4 & $z_{1} \geq 767975.00$ & $\operatorname{Min} z_{2}$ & $z_{3} \leq 13645.45$ & 984176.00 & 144731.33 & 13645.40 \\
\hline 5 & $z_{1} \geq 767975.00$ & $z_{2} \leq 154893.26$ & $\operatorname{Min}_{z_{3}}$ & 767984.00 & 148905.34 & 12430.30 \\
\hline \multirow[t]{2}{*}{6} & $z_{1} \geq 767975.00$ & $z_{2} \leq 144035.62$ & $\operatorname{Min} z_{3}$ & & & \\
\hline & & & & 1144399.00 & 144035.57 & 13987.20 \\
\hline
\end{tabular}


In $\varepsilon$-constraint method, in maximizing $z_{1}$ and minimizing $z_{2}$ cases, $\varepsilon$-constraint level of $z_{3}$ affects the values of $z_{1}$ and $z_{2}$ substantially. Tight $\varepsilon$-constraint level of $z_{3}$ causes deterioration in $z_{1}$ and $z_{2}$. Similarly in minimizing $z_{3}$ case, $\varepsilon$-constraint levels of $z_{1}$ and $z_{2}$ affect level of $z_{3}$. For illustration, network configuration of first planning period obtained by experiment 2 of $\varepsilon$-constraint method is shown in Figure 3.

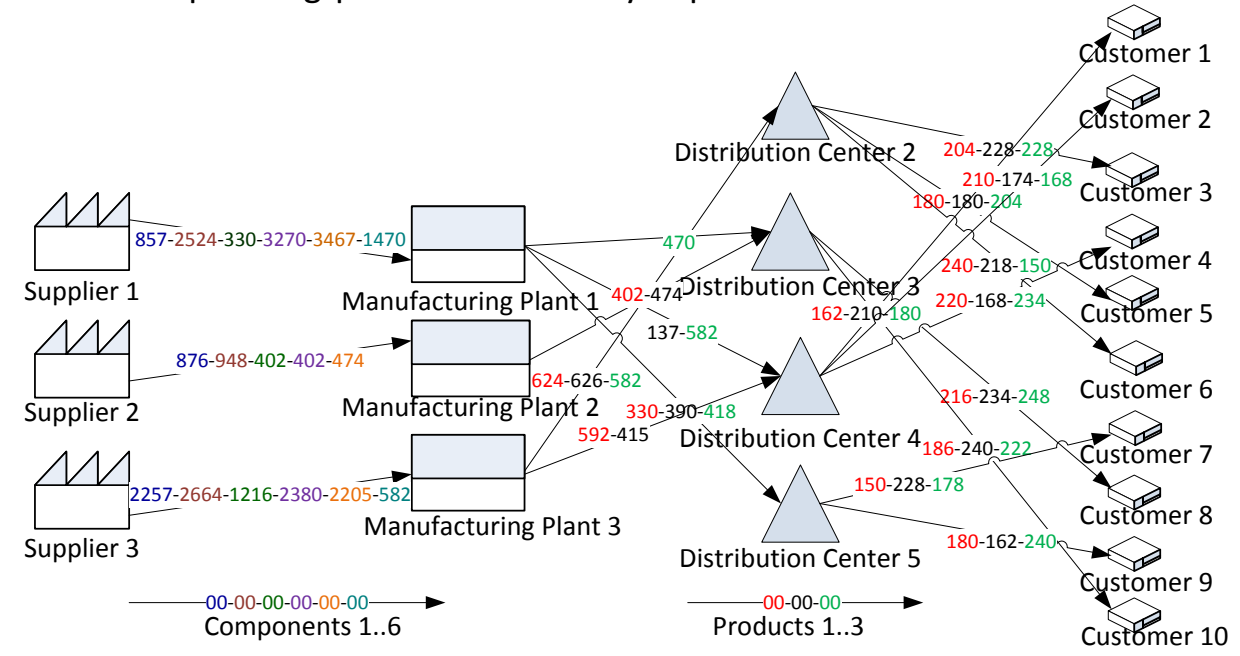

Figure 3. Network configuration for period 1

\section{Conclusions}

This paper addresses the multi-stage, multi-product, multi-component and multi-period green supply chain network design problem. A multi-objective optimization model is developed to obtain best network configuration for economic and environmental performance of the green chain. In multiobjective frame of the proposed model, total profit maximization, $\mathrm{CO}_{2}$ emissions minimization caused from transportation and environmental impact minimization caused from opening new plants or distribution centers/warehouses and manufacturing and handling processes based on used clean technology, recyclable materials, renewable energy etc. are considered. Applicability of the model is presented with numerical experiments. Attained results showed that the model produces effective and efficient solutions for conflicting economic and environmental objectives. The proposed model can be used as a supportive tool for multi objective decisions in green supply chain problems to obtain preferred results according to the importance of each objective function.

\section{References}

Aksoy, A., Kucukoglu, I, Ene, S., \& Ozturk, N. (2014). Integrated emission and fuel consumption calculation model for green supply chain management. Procedia-Social and Behavioral Sciences,109, 1106-1109.

Amin, S.H., \& Zhang, G.(2013). A multi-objective facility location model for closed-loop supply chain network under uncertain demand and return. Applied Mathematical Modelling, 37, 4165-4176.

Chibeles-Martins, N., Pinto-Varela, T., Barbosa-Povoa, A.P., \&Novais, A.Q. (2016). A multi-objective metaheuristic approach for the design and planning of green supply chains-MBSA. Expert Systems With Applications, 47, 71-84.

Coskun, S., Ozgur, L., Polat, O., \&Gungor, A. (2016). A model proposal for green supply chain network design based on consumer segmentation. Journal of Cleaner Production, 110, 149-157.

Elhedhli, S., \& Merrick, R.(2012). Green supply chain network design to reduce carbon emissions.Transportation Research Part D, 17, 370-379. 
Ene, S. \& Ozturk, N. (2017). Multi-objective green supply chain network optimization. Global Journal of Business, Economics and Management: Current Issues. 7(1), 15-24.

Fahimnia, B., Sarkis, J., \& Eshragh, A. (2015). A tradeoff model for green supply chain planning: A leannessversus-greenness analysis. Omega, 54, 173-190.

Govindan, K., Khodaverdi R., \&Vafadarnikjoo, A. (2015). Intuitionistic fuzzy based DEMATEL method for developing green practices and performances in a green supply chain. Expert Systems with Applications, 42, 7207-7220.

Pishvaee, M.S., \&Razmi, J. (2012). Environmental supply chain network design using multi-objective fuzzy mathematical programming. Applied Mathematical Modelling, 36, 3433-3446.

Marti, J.M.C., Tancrez, J-S., \&Seifert, R.W. (2015). Carbon footprint and responsiveness trade-offs in supply chain network design. International Journal of Production Economics, 166, 129-142.

Srivastava, S.K. (2007). Green supply chain management: A state-of-the-art literature review. International Journal of Management Reviews, 9(1), 53-80.

Tognetti, A., Grosse-Ruyken, P.T., \& Wagner, S. M. (2015). Green supply chain network optimization and the trade-off between environmental and economic objectives. International Journal of Production Economics, 170, 385-392.

Varsei, M., Soosay, C., Fahimnia, B., \& Sarkis, J.(2014). Framing sustainability performance of supply chains with multidimensional indicators. Supply Chain Management: An International Journal, 19(3), 242 - 257. 